\title{
Ventricular fibrillation and initial plasma potassium in acute myocardial infarction
}

\author{
RODERIC D. THOMAS \\ M.D., M.R.C.P. \\ Royal United Hospital, Bath
}

\begin{abstract}
Summary
In a retrospective review of patients admitted to a coronary care unit, 809 patients had a definite myocardial infarction and plasma potassium was measured within $48 \mathrm{hr}$. The mean ( \pm s.d.) plasma potassium was $4.04( \pm 0.56) \mathrm{mmol} / \mathrm{litre}$. A potassium concentration of less than $4 \cdot 0 \mathrm{mmol} /$ litre was found in 383 patients, of whom 14 had ventricular fibrillation. A potassium concentration of $4.0 \mathrm{mmol} / \mathrm{litre}$ or greater was found in 426 patients, of whom 3 had ventricular fibrillation, a difference significant at the $0.4 \%$ level ( $\chi^{2}$ test). Preceding diuretic therapy did not appear to be relevant and there appeared to be no other difference between the two groups. The maintenance of a high-normal plasma potassium, or the prevention of its reduction, in patients with an acute myocardial infarction may be important.
\end{abstract}

KEY WORDS: myocardial infarction, hypokalaemia, arrhythmias.

\section{Introduction}

The clinical significance of a low plasma potassium concentration in patients continues to attract attention (Sandor, Pickens and Crallan, 1982). Observations over many years have linked arrhythmias with a low potassium (Davidson and Surawicz, 1967), though serious ventricular arrhythmias appear rare and have usually only been associated with potassium levels of less than $3.2 \mathrm{mmol} /$ litre (Curry et al., 1976). There is evidence that the frequency of arrhythmias might be increased in patients with an acute myocardial infarction and a low potassium concentration (Dyckner et al., 1975) and the arrhythmias include ventricular fibrillation (Beck and Hochrein, 1977). These are important observations which have been studied in a retrospective survey.

\section{Patients, methods and results}

The notes of all the patients admitted to the coronary care unit of the Royal United Hospital,
Bath, with a suspected myocardial infarction, from 1974 to 1980 were reviewed. Definite myocardial of infarction was diagnosed using accepted criteria and 8 arrhythmias were detected on bedside and central $N$ nursing station oscilloscopes and recorded on a rhythm strip.

Eight-hundred-and-nine patients had an acute $\stackrel{\circ}{\Im}$ myocardial infarction and a plasma potassium mea- $\vec{c}$ sured within $48 \mathrm{hr}$ and before any major complica- $\frac{\varsigma}{5}$ tion. Their average age was $60 \cdot 1$ years (s.d. $\pm 10 \cdot 4 \stackrel{\oplus}{\oplus}$ years). The exact timing of the potassium measure $\vec{\oplus}$ ments cannot be examined retrospectively; $72 \%$ of the patients had the measurements within $24 \mathrm{hr} \&$ admission. In Table 1, the patients are divided into groups at a potassium level of $4 \mathrm{mmol} /$ litre. There were significantly more patients with ventricular fibrillation in the group with the lower potassium $\stackrel{\circ}{\mathbb{Q}}$ (significant at the $0.4 \%$ level, $\chi^{2}$ test). The mean plasma potassium of all 17 patients with ventricular fibrillation (VF) was 3.67 (s.d. 0.37) $\mathrm{mmol} / \mathrm{litre}$, and this was significantly lower at the $0.1 \%$ level than those without ventricular fibrillation. Analysis of the potassium measurements in the group with a plasma concentration $<4 \mathrm{mmol} /$ litre gave a mean ( \pm s.d.) of those with VF $(n=14)$ of $3 \cdot 54 \pm 0 \cdot 29$, while that of the 3 . remainder of the patients $(n=369)$ was $3 \cdot 60 \pm 0 \cdot 28$. The mean time of admission after onset of symptoms, $\frac{3}{3}$ which was recorded in about $80 \%$ of patients, was 2.4 hr (s.d. 2.4). The mean time of admission in all patients with ventricular fibrillation was $1.94 \mathrm{hr}$ (s.d. $\frac{7}{2}$ 1.4 ) and in the group with a lower potassium it was $2.0 \mathrm{hr}$ (s.d. 1.2). There were no significant differences $\mathcal{O}$ in the numbers with supraventricular arrhythmias $N$ (atrial flutter, atrial fibrillation or supraventricular $\mathrm{N}_{0}$ tachycardia) or various forms of intra-ventricular $\omega$ block (second degree complete atrioventricular block or bundle branch block). There was also no difference in the numbers of patients on previous therapy with diuretics or beta-blocking drugs in each group : and the number of patients on digoxin was the same. There did not appear to be any obvious difference in the site or severity of infarction in the two groups. 
TABLE 1. Observations in two groups of patients with acute myocardial infarction: arrhythmias noted within $48 \mathrm{hr}$ of admission

\begin{tabular}{lcc}
\hline & $\begin{array}{c}\text { Initial } \\
\text { plasma potassium } \\
\end{array}$ & $\begin{array}{c}\text { concentration }(\mathrm{mmol} / \mathrm{l}) \\
\geqslant 4 \cdot 0\end{array}$ \\
\hline Number of patients & 383 & 426 \\
Mean age (years) & $59 \cdot 8$ & $60 \cdot 4$ \\
Plasma potassium (mean \pm s.d.) & $3 \cdot 6( \pm 0 \cdot 3)$ & $4 \cdot 4( \pm 0 \cdot 5)$ \\
Ventricular fibrillation & 14 & $3 *$ \\
Supraventricular arrhythmias & 18 & $28 \dagger$ \\
Atrioventricular block & 30 & $51 \dagger$ \\
On diuretic therapy & 49 & $48 \dagger$ \\
On beta-blockade therapy & 22 & $30 \dagger$ \\
\hline
\end{tabular}

${ }^{*} P<0.005\left(\chi^{2}-\right.$ test $) ;$ †not significantly different.

An additional 11 patients had their plasma potassium measured immediately after an episode of ventricular fibrillation. The mean was 3.36 (s.d. 0.54 ) $\mathrm{mmol} /$ litre and these low levels were not explained by alkalosis on the basis of a normal simultaneous arterial $\mathrm{pH}$ in most of those with the lowest levels. Finally, there were 10 patients with ventricular fibrillation after the first $48 \mathrm{hr}$ (mean 4.5 days) and these did not have such low levels of potassium (mean 3.92, s.d. $0.44 \mathrm{mmol} /$ litre).

\section{Discussion}

This study has shown a significant increase in the number of patients with early ventricular fibrillation in association with reduced plasma potassium concentration. It confirms the original observations and is strongly supported by the findings of other groups reported in a recent symposium (Solomon and Cole, 1981; Nordrehaug, 1981; Hulting, 1981). Similar results were obtained in a study in Birmingham (Reuben, personal communication) and the patients over 65 years old in these two studies were combined in a recent report (Reuben and Thomas, 1982). The relevance is supported by the theoretical background of arrhythmias (Fisch, 1933) and experimental studies which show an increased incidence of ventricular fibrillation in the presence of hypokalaemia (Daugherty and Woodward, 1981).

It may be necessary to separate the problem of diuretic-induced hypokalaemia from that found in acute myocardial infarction. The former is common and has been shown to be associated with increased ventricular ectopic activity (Holland, Nixon and Kuhnert, 1981). However, it is not known whether the incidence of serious arrhythmias is increased, although some authors have speculated that this is so. In myocardial infarction, it may be that the hypokalaemia is related to another factor (or factors) which is in itself arrhythmogenic. For example, one of the contenders for this is adrenaline, which is increased in myocardial infarction, can lower plasma potassium and is arrhythmogenic (Struthers et al., 1981).

Though the situation is complex and merits prospective study, these observations suggest that it may be prudent to try and maintain a high-normal plasma potassium concentration, or prevent its reduction, in patients with an acute myocardial infarction.

\section{Acknowledgment}

I would like to thank Sarah Hicks, SRN, for her help with the note review.

\section{References}

BECK, O.A. \& Hochrein, H. (1977) Initial serum potassium level in relation to cardiac arrhythmias in acute myocardial infarction. Zeitschrift fur Kardiologie, 66, 187.

Curry, P., Fitchett, D., Stubbs, W. \& Krikler, D. (1976) Ventricular arrhythmias and hypokalaemia. Lancet, i, 231.

DAUgherTY, A. \& WoODWARD, B. (1981) $\mathrm{K}^{+} / \mathrm{Ca}^{++}$ratio and calcium slow channel antagonists on arrhythmias in the isolated perfused coronary ligated rat heart. British Journal of Pharmacology, 74, 834P.

Davidson, S. \& SURAwicz, B. (1967) Ectopic beats and atrioventricular contraction disturbances. Archives of Internal Medicine, 120 , 280.

DyCKNer, T., Helmers, C., Lundman, T. \& Webster, P.O. (1975) Initial serum potassium level in relation to early complications and prognosis in patients with acute myocardial infarction. Acta medica Scandinavica, 197, 207.

FISCH, C. (1933) Relation of electrolyte disturbances to cardiac arrhythmias. Circulation, 47, 408.

Holland, O.B., Nixon, J.V. \& Kuhnert, L.V. (1981) Diureticinduced ventricular ectopic activity. American Journal of Medicine, 70, 762.

HultiNG, J. (1981) In-hospital ventricular fibrillation and its relation to serum potassium. Acta medica Scandinavica (Suppl.) 647, 109.

NORDREHAUG, J.E. (1981) Malignant arrhythmias in relation to serum potassium values in patients with an acute myocardial infarction. Acta medica Scandinavica (Suppl.) 647, 101.

REUBEN, S.R. \& THOMAS, R.D. (1982) The relationship between serum potassium and cardiac arrhythmias following cardiac infarction in patients over 65 years. Current Medical Research and Opinion, 7 (Suppl.), 79.

Sandor, F.F., Pickens, P.T. \& Crallan, J. (1982) Variations of plasma potassium concentrations during long-term treatment of 
hypertension with diuretics without potassium supplements. British Medical Journal, 284, 709.

Solomon, R.J. \& COLE, A.G. (1981) Importance of potassium in patients with acute myocardial infarction. Acta medica Scandinavica (Suppl.) 647, 87.
Struthers, A.D., Reid, J.L., MCLean, K. \& Rodger, J.C. (1981) Adrenaline, hypokalaemia and cardiac arrhythmias: effects of beta adrenoceptor antagonists. Clinical Science, 62, 1p.

(Accepted 7 December 1982) 